\title{
DOS INDÍCIOS PERVERSOS À SENTENCIAÇÃO DA LOUCURA SOCIAL: O CASO DA MENINA VAMPIRO DO PIAUÍ1
}

\author{
Carla Danyelle Desidério Freitas ${ }^{2}$ \\ Alexandre Christian de Jesus Nolêto ${ }^{3}$
}

\begin{abstract}
RESUMO: O artigo pretende associar um episódio de grande repercussão do Estado do Piauí, popularmente conhecido como o caso da menina-vampiro, às especialidades necessárias à teoria criminológica com a pretensão de crítica à expiação das duas situações mais estigmatizantes da sociedade: o crime e a loucura. Para tanto, será necessário a priori desmitificar o sensacionalismo midiático, em uma perspectiva de crítica à tentação do instinto punitivista e à essência ontológica do crime. Além disso, imprescindível é reconhecer evidências da desídia estatal em face de sua pretensão punitiva, o que resulta em um estigmatizante processo de criminalização alheio aos princípios e direitos fundamentais amparados pela Constituição. Anseia-se, ao fim, entender a medida da psicopatologia diagnosticada, o juízo de imputabilidade decorrente e as medidas cabíveis à luz da técnica jurídica, de modo a incitar a contrapartida do cidadão ativo, participante dos processos históricos e das consolidações dos princípios fundamentais, para insurgir em favor do devido processo legal penalista em oposição à sentenciação da loucura social.
\end{abstract}

Palavras-chave: crime, loucura, punitivismo, psiquiatria, criminologia.

\section{FROM PERVERSES EVIDENCES TO THE SENTENCING OF SOCIAL MADNESS: THE CASE OF THE VAMPIRE-GIRL}

\begin{abstract}
The paper intends to associate the episode of great impact of the state of Piauí, popularly known as the case of the vampire-girl, to the specialities necessary for the criminological theory, intending to criticize the atonement of the two most stigmatizing situations of society: crime and insanity. For such purpose, it will be necessary, a priori, to demystify media's sensationalism, in a perspective of critic to the temptation of the punitive instinct and to the ontological essence of crime. Moreover, it is indispensable to recognize evidences of the state's negligence in face of it's punitive intention, which results in a stigmatizing process of criminalization strange to the principles and fundamental rights supported by the Constitution. It is intended, after all, to understand the measure of the diagnosed psychopathology, the judgment of arising imputability and the needed measures by the light of legal techniques, in order to encourage the counterpart of the active citizen, participant of the historical processes and of the consolidation of the fundamental principles, to rebel in favor of the due punitive legal process in opposition to the sentencing of social madness.
\end{abstract}

Keywords: crime, insanity, punitivism, psychiatry, criminology.

\footnotetext{
${ }^{1}$ Artigo recebido em 15/06/2014 e aprovado em 02/03/2016

${ }^{2}$ Acadêmica do $8^{\circ}$ período do curso de direito da Universidade Federal do Piauí

${ }_{3}^{3}$ Advogado, Consultor Jurídico, Parecerista e Professor. Especialista em Direito Público. Mestrando em Direito Constitucional.
} 


\section{Introdução}

$\mathrm{O}$ crime e a loucura. As duas situações mais estigmatizantes de uma sociedade, vinculadas a um dos acontecimentos de maior repercussão do Estado do Piauí: o caso da menina-vampiro.

É esse título que subscreve o romance "15:50" de Eneas Barros. Uma narrativa de reconstituição dos fatos à sucessão daquela trágica tarde de novembro de 1998 (BARROS, 2010, p. 15). Tudo o que nele foi escrito, "além de algumas impressões pessoais, foi baseado em farta documentação, na reflexão de juristas, nos pareceres profissionais que acompanharam o caso e no testemunho de parentes e das muitas pessoas que estiveram na cena do crime" (BARROS, 2010, p. 16).

No entanto, o constante material produzido pela imprensa à época não reproduz a mesma lucidez da narrativa de Eneas Barros, fundamentada em fontes históricas idôneas. Por isso, fazendo uso do caso da menina-vampiro, questionar-se-á, como cerne da presente análise, a coincidente expiação do crime de que tanto se preocupa a opinião pública. O que se percebe é a supressão da carência de informações da mídia pela censura do suspeito, do indiciado, do acusado ou do condenado, para manter a atenção e a curiosidade social, de modo a alimentar a emissão de opiniões. Há um compromisso oportunista de vincular o crime ao extraordinário, já que tudo o que o é desperta interesse.

Diante desse espetáculo do crime no seio social, não há a consideração de um princípio do estado de inocência ${ }^{4}$, como propõe o Estado Democrático de Direito brasileiro. Mas uma presunção de culpabilidade: pela averiguação, e até sugestão, de qualquer indício na vida pregressa que prenuncie uma conduta violenta no futuro. Nesse sentido, o criminoso não é sentenciado apenas pelo crime. É condenado, também, a se expor à sociedade. Daí porque o que seria uma mera característica humana de diferenciação passa a ser, aos olhos do processo inquisitório social, um aspecto de íntima propensão natural ao crime. Quando, em verdade, a essência criminológica tem, em regra, outra direção: os rótulos sociais.

Há uma inquisição da coletividade que condena o transgressor a se sujeitar aos seus iguais ${ }^{5}$, de modo a tornar sua existência social árdua. Isso porque a ignorância personific ada

\footnotetext{
4 Artigo 5o, inciso LVII, Constituição Federal de 1988. Em igual sentido: Art. $9^{\circ}$, Declaração dos Direitos do Homem e do Cidadão/1789 ("Todo homem é considerado inocente, até o momento que, reconhecido como culpado, se julgar indispensável a sua prisão: todo o rigor desnecessário empregado para efetuar, deve ser severamente reprimido pela lei").

${ }^{5}$ Iguais porque todos são criminosos. Basta lembrar o exemplo de Nilo Batista (2007, p.88) que ilustra o conceito de cifra oculta: "Podemos acreditar ou não que o número de carros que ultrapassam a velocidade permitida
} 
tende a pré-julgar e a lembrar da manifestação de uma periculosidade que possivelmente lhe tomará o fôlego e o fará delinquir novamente.

No cerne dessa crítica à expiação do crime e do criminoso, é que este trabalho pretende revisitar o caso de Luíza, à luz de uma análise integrada ${ }^{6}$ - servindo-se de todos os argumentos e de todas as especialidades necessárias à teoria criminológica. A pretensão cerra-se em (I) desmitificar o sensacionalismo midiático, numa tentativa de (II) entender a medida de sua psicopatologia, (III) o juízo de imputabilidade e (IV) as procedências cabíveis informadas pela técnica jurídica.

Mencionou-se o caso de Luíza em substituição ao rótulo divulgado pela opinião pública - o caso da menina-vampiro. Inicialmente, com a mesma pretensão original de Eneas Barros quando the atribuiu um pseudônimo no livro 15:50: para preservar o seu anonimato (BARROS, 2010, p. 16). No entanto, anseia-se por transcender o estigma social de associação do crime ao extraordinário e à loucura. É imprescindível iniciar com a readequação das referências ao acontecido para ambicionar a abordagem realista apetecida pelo método jurídico.

E essa readequação da análise criminal do caso exposto tenderá a uma crítica às instituições correcionalistas e psiquiátricas. Será indispensável, portanto, "reinventar os discursos e práticas humanistas na era do punitivismo e do encarceramento em massa" (CARVALHO, 2013a, p. 286) e despir-se das pré-concepções perpetuadas no senso comum, para, enfim, pretender chegar à verdade contingencial ${ }^{7}$.

No entanto, apesar da crise - ou imprecisão - paradigmática das ciências criminais, a criminologia não é uma ciência linear e evolutiva. Ela é feita de rupturas e permanências (BATISTA, 2012, p. 17), tal qual a história. O positivismo como a grande permanência; e a criminologia crítica como a saudosa ruptura, que, entretanto, também não deve perdurar. Isso

('criminalidade') é idêntico ao número de multas impostas, sob esse motivo pelas autoridades de trânsito (criminalização); mas é apenas neste segundo número, em verdade um construto humano (na dependência de fatores tão distintos quanto os humores do guarda, a localização da câmara de vigilância etc.), que poderemos estudar a incidência das transgressões".

${ }^{6}$ A análise integrada não diz respeito ao estudo interdisciplinar orientado pelo paradigma etiológico e causal do positivismo. Não pretende invadir o senso comum do homem de rua (every day theories) no que tange à compreensão sobre o crime (ente natural), o criminoso (atávico) e a pena (regeneradora). Mas refere-se à abertura interdisciplinar que pretende romper com o dogmatismo: abandonar a vontade de sistema, desobrigar-se do rótulo de cientificidade e eximir-se da pretensão de verdades definitivas e unidades totalizantes. Não buscará, portanto, modelos integrados de ciências criminais, mas inventará espaços de integração de saberes críticos. (CARVALHO, 2013a, p. 109-111)

${ }^{7}$ Pretende-se uma investigação fundada em atos de convencimento, tal qual a sentença processual de Aury Lopes Jr. (2013, p. 575): "Se isso coincidir com a 'verdade', muito bem. Importa é considerar que a 'verdade' $e$ contingencial, e não fundante". 
porque "a totalização dos métodos científicos exclui qualquer hipótese de reconhecimento das diferenças e das identidades, seja dos sujeitos implicados, pois são reduzidos a objetos de investigação, ou das formas de análises, em decorrência do enclausuramento disciplinar e metodológico" (CARVALHO, 2013a, p. 114). Por isso, será necessária a perspectiva de uma criminologia integrada: já que inúmeros são "os fatores, as variáveis e os acasos que atuam nas e sobre as diversas pessoas que cometem os mais diferentes atos em circunstâncias absolutamente distintas de tempo, local e forma de agir - fatores que tornam inconsciente qualquer individuação" (CARVALHO, 2013, p. 122).

Nessa perspectiva, seguir-se-á a narração da tarde fatídica às 15:50 . E o cunho apelativo da descrição do crime objeto do artigo será proposital. Trivialmente para motivar - ou apenas ilustrar - o sentimento punitivo ou vinculador da exigência por justiça evidenciado no senso comum.

\title{
2. Do monstro ao cabo do machado 9
}

\begin{abstract}
Um pesadelo que a levou a um sono entrecortado. (...) Sonhou que passeava pelo cais quando uma enorme figura, um monstro, surgiu de dentro d'água e a levou para o fundo. Debatia-se inutilmente, lutando para não se deixar levar, mas o monstro mergulhou para as profundezas de um lugar desconhecido, turvo, tão misterioso que ela não conseguia entender onde estava. Depois de muito esforço, conseguiu desvencilhar-se e nadou até um tronco imenso que repousava no fundo do rio. Respirava com dificuldade, procurando ar. Ao lado do tronco, viu u m machado que lhe parecia familiar. Quando o monstro resolveu investir contra ela, para imobilizá -la, revidou e o agrediu mortalmente. Bateu por diversas vezes, enquanto as águas turvas do rio se avermelhavam do sangue que se esvaía de seus golpes certeiro s. Olhou para cima e viu uma forte claridade. Acordou com os raios de sol penetrando as frestas de sua janela e a atingindo no rosto.

A hora se aproximava. O sonho havia sido um sinal. (BARROS, 2010, p. 25-26).
\end{abstract}

Nessa vertente de uma alegoria de caráter poético, Eneas Barros (2010) narra o episódio que aflorou a emoção até mesmo dos mais insensíveis e cuja repercussão ultrapassou as fronteiras do Estado do Piauí.

A sobrinha que assassinou a machadadas sua tia e sua prima - de quatro anos incompletos - e que deixou, numa tentativa falha de assassinato, outra prima - de cinco anos

\footnotetext{
8 "O momento havia chegado. (...) Olhou mais uma vez para a tia e para a prima. (...) Segurou com firmeza o cabo do machado. O relógio da sala marcava 15:50.” (BARROS, 2010, p.28).

${ }^{9}$ Como já antecipado, este tópico possui uma linguagem apelativa, numa tentativa de retratar a forma como o noticiário tradicional costuma descrever esse tipo de crime. De modo algum essa narrativa reproduz as inclinações da autora.
} 
incompletos - com graves sequelas físicas e psicológicas. Como se não bastasse, para saciar sua sede de sangue, descrita anteriormente num diálogo com uma das vítimas, serviu-se do líquido viscoso avermelhado que jorrava da confusão entre o crânio e a massa encefálica dos corpos. Constatou o "gosto de leite morno com sal" (BARROS, 2010, p. 30).

Após o crime, estava impaciente por esperar seu tio no regresso ao lar, para contra ele investir semelhantes golpes que the tirariam a vida. E então estaria livre daquela família que a sufocava, que tolhia sua liberdade e que tanto the aguçava inveja. A verdade era essa: não suportava a ideia da família perfeita. Nunca seria uma filha para seus tios (BARROS, 2010, p. 29). O mais prático seria se livrar dos quatro da forma mais eficiente. E estaria livre. Mas o tio parecia ter desistido de voltar para casa, quase como se adivinhasse o risco de um destino perverso.

A moça, então, resolveu tomar um bom banho para livrar-se do sangue, que só lhe parecia agradável enquanto degustado. E assim o fez. Limpou-se, serviu-se das roupas e da bolsa de alguém que outrora a tinha acolhido quando em desamparo - sua tia -, mas que agora se resumia ao gosto de leite morno com sal. E saiu para conversar na casa vizinha. Assim: como se nada tivesse acontecido. Como se todas as atrocidades anteriormente cometidas não passassem de meros episódios de um pesadelo. E que agora, desperta, estaria livre.

Mas não tardou para que sua fuga dissociativa a denunciasse. Que louco pensaria que bastava tomar um banho e sair para conversar com a vizinhança para que automaticamente sua presença óbvia fosse descaracterizada da cena do crime? Uma íntima perversidade translúcida. Insanidade. Que apodreça encarcerado o doente mental que ao crime deu a vida e à vítima deu a morte.

\section{A tentação do instinto punitivista e a essência ontológica do crime}

É assim que a opinião pública leva a pensar o homem médio. Investida desse mesmo fascínio pelo sensacionalismo. O instinto punitivista que cerca o cidadão e que the entrega argumentos prontos a serem reproduzidos. Um discurso que se serve de uma fragilidade política ansiosa por justiça - decorrente de sistemas democráticos que não dão voz audível (PETTIT, 2007) à realidade complexa da pluralidade de minorias - e que ainda se pauta na tetralogia de valores (NIETZSCHE, 1998): bondade, beleza, verdade e justiça.

Além disso, há a instigação pelos governantes desse aparente clamor por justiça. A partir dele se fazem os grandes palanques eleitorais. É a perpetuação cultural do temor ao crime, de 
modo a impor a insegurança, a ansiedade e o pânico relativos àqueles selecionados como criminosos ou estigmatizados como doentes mentais pelo sistema penal. Esse pavor gera o sentimento de despotencialização do coletivo, que leva à apatia e ao desânimo (RAUTER, 2010, p. 196) e à prenunciação da alternativa óbvia: a punição.

É exatamente essa estratégia da difusão do medo que a manchete do jornal do dia subsequente ao caso faz uso: "Crimes macabros abalam Floriano". E continua:

\footnotetext{
"Uma pequena casa (...) foi palco de cenas só vistas em filmes de terror. (...) Presa, a as sassina disse que estava dormindo quando, ao acordar, viu as três (vítimas) deitadas no chão e decidiu matá-las. Depois do crime, ela ainda disse ter bebido três copos de sangue" (O DIA, 1998).
}

Diante dessa associação entre a opinião pública e o populismo punitivistas, há um redirecionamento das políticas de efetivação da cidadania para as promessas de uma segurança pública que nunca será alcançada (ou pelo menos não da forma prometida). São as propostas de altas penas, castigos degradantes, maus tratos, desconsideração das garantias fundamentais e processuais: "atacam os criminosos em vez de atacarem a violência estrutural (a desigualdade social e a pobreza)" (ARGÜELLO, 2012, p. 207). É o que Maurício Martínez (2010, P. 313) descreve como o populismo punitivo contemporâneo: servido do complexo do delito, na direção de uma política criminal de tolerância zero (Garland apud MARTÍNEZ, 2010, p. 314) e em favor de um Direito Penal do Inimigo (JAKOBS, 1985).

Essas trivialidades de argumentos ensejam, ainda, o que Salo de Carvalho chama de o fascínio pela violência, denunciado como as feridas da cultura ocidental e do processo civilizatório (CARVALHO, 2013, p. 25). O caráter humano se rende facilmente às expectativas de crueldade e sofrimento impostas às vítimas ${ }^{10}$, seja pelo lado sombrio individual - no desdobrar do ato criminoso - ou pelo sistema punitivo - na execução da pena. Isso quando não se incita a volta à vingança privada. Não é uma perda de legitimidade do sistema em razão de uma brandura excessiva: é apenas a incitação à vontade de cada vítima vingar-se, para que tal fato não torne a se repetir.

É evidente que a massa social fomenta a opinião pública e o populismo punitivistas. O homem contemporâneo ainda guarda resquícios da barbárie e da vingança privada: uma exigência impulsiva e insaciável do que se apelida equivocadamente de justiça. E de forma

\footnotetext{
10 Vítimas em sentido amplo: tanto criminosos - vítimas do sistema -, quanto as vítimas dos criminosos.
} 
diversa não foi o comportamento social no caso de Luíza. A sociedade se achava merecedora de uma pré-inquisição: "o crime revoltou a população, que se aglomerou diante da delegacia" (O DIA, 1998). E ainda: "Havia muita comoção pelas ruas. A população pretendia fazer justiça com as próprias mãos. Discutiam inclusive a ideia de linchamento. Enquanto a notícia voava pelos quatro cantos, com ela seguia o clamor social" (BARROS, 2010, p. 48).

Portanto, como pondera Tércio Ferraz Júnior: "a violência (enquanto vis, força) está ligada à natureza do homem" (FERRAZ JR., 1979, p. 1). Isso denuncia o quanto os projetos civilizatórios da modernidade são falhos. E, acrescentar-se-ia, paradoxais. Porque os cidadãos são levados a pensar e a argumentar, com uma ficta inconsciência, contra seus direitos e garantias fundamentais. Renegam a democracia constitucionalista em favor de seus falsos momentos revolucionários, de modo a alegar a soberania do majoritário; mas sem atentar que o tirano também veste a fantasia das massas.

E esse discurso positivista, que segue no senso comum, cerca-se da pretensão de cientificidade da criminologia para reproduzir a investigação do crime em uma perspectiva ontológica. A criminalidade é tida como algo natural a determinados indivíduos, de modo que seu comportamento se reduz ao crime. São as respostas das causas do delito que defende Lombroso (1983), com sua tese do criminoso nato. Ou a tríplice ordem de causas - orgânicas e psíquicas, ambiente telúrico e ambiente social - de Ferri (1931). E, sendo o crime inerente ao criminoso, há uma temibilidade do delinquente (GAROFALO, 1983), sempre direcionada na expectativa de sua reincidência: é o que posteriormente conceituou-se no termo periculosidade.

Há um estigma determinante da criminalidade e, por isso, é necessária uma defesa social dessas personalidades perigosas que põem em risco a ordem pública. O criminoso é tratado como um doente mental, cuja pena seria o remédio para curá-lo e torná-lo apto ao convívio em comunidade. O crime torna-se $o$ evento da história de vida do agente: há uma sugestão de indícios mínimos dos fatos que deram causa ao delito. Condutas que são normais ao comportamento humano passam a fazer parte do inter criminis, da causa regressa ao infinito ou de seus exaurimentos. É o que Jock Young designa como essencialização do crime e do criminoso (YOUNG, 2002).

Foi essa perspectiva, de atribuições indevidas de doença mental, da culpa regressa ao infinito e da periculosidade, que previamente julgou e condenou Luíza à estigmatização social: 
D.F. ${ }^{11}$ morou em São Paulo durante um ano, na casa de parentes, que a mandaram de volta para o Piauí em razão de suas atitudes violentas. Ela teria, inclusive, tentado matar uma prima menor estrangulada com uma corda, mas foi impedida pela mãe da vítima. Os próprios pais dela, que residem em Floriano, não aceitavam mais que ela morasse com eles, temendo suas atitudes violentas. Os únicos que aceitaram foram Raimunda Maciel e o marido Francis co José, sem saber que is so culminaria com uma tragédia nunca vista no município ou qualquer outro do Piauí. (O DIA, 1998, p. 7).

E, conforme esse paradigma - de que decorre a condenação social de Luíza - existem dois grupos na sociedade: o da anormalidade criminosa e o dos indivíduos que vivem conforme o contrato social. No entanto, é necessário entender a criminalidade para além do bem e do mal (NIETZSCHE, 2002). Isso porque, em verdade, o que se evidencia dos argumentos dos típicos homens médios punitivistas é uma associação ao paradigma etiológico da criminologia, do qual vêm emergindo, nos últimos contextos, dissidências.

\section{Evidências: da desídia estatal à criminalização}

A mais evidente dessas cisões é denunciada na teoria do labelling approach (BECKER, 1971) (etiquetamento), que, associada aos conceitos de cifra oculta ${ }^{12}$ e de reação social, abre margem a uma análise macrossociológica (BARATTA, 2002) da criminalização. Nesse casamento feliz, que conduz a uma criminologia crítica, o crime passou a ser o resultado, em regra, não de uma conduta patológica. Mas de (I) uma tipificação legislativa (definição) associada a (II) um estigma do que venha a ser uma conduta anormal, atribuída ao dito criminoso pela Polícia e pela Justiça (seleção) (ANDRADE, 1995, p. 28). Há, portanto, uma integralização sistemática do processo de criminalização seletiva. E o papel do Direito Penal é conter os rotulados criminosos anormais, para garantir a ordem e a segurança de uma sociedade que tem por contrato social um acordo de interesses entre as elites.

O que é evidente, diante desse paradigma da rotulação, é que o comportamento de Luíza não só foi objeto de uma tipificação legislativa, como (e aqui se situa a gravidade e a contradição maior) foi selecionado e estigmatizado, ao longo de todo o seu desenvolvimento como pessoa, pelo exercício - ou omissão negligente - do poder estatal. Diz-se grave e, principalmente, contraditório porque o mesmo Estado que detém o monopólio da pretensão punitiva - e que a

\footnotetext{
${ }^{11}$ Buscou-se mudar as iniciais (e apenas) em prejuízo do texto original para atentar ao disposto no art. 143, parágrafo único, da Lei 8069/1990 (Estatuto da Criança e do Adolescente).

${ }^{12}$ Cifra oculta é como a doutrina costuma conceituar a discrepância entre o número de crimes que, de fato, são cometidos e aqueles que são alvo do processo de criminalização.
} 
efetivou - é o mesmo que tutela pelo menos quatro princípios fundamentais, informados pela Constituição Federal e pelo Estatuto da Criança e do Adolescente, imediatamente associados à situação de risco em razão da conduta de Luíza. Explica-se.

No livro "15:50", Eneas Barros atenta para o fato de que "as evidências se manifestavam, tomando forma para explicar o intricado processo que a levou a cometer aquele ato insano" (2010, p. 67). No entanto, é imprescindível desconsiderar essa busca insaciável de indícios, mínimos do que sejam, de que futuramente ocorreria um crime violento. É preferível permanecer na temática crítica da presente análise e evitar o perigo da expiação e da culpa regressa ao infinito atribuída ao agente (ou suspeito).

De fato, quase vitimar uma criança quando ainda tinha 12 anos, constantes fugas, não frequência à escola pública em que estava matriculada, tentativa de esganamento a um rapaz que a tentou estuprar (2010, p. 64-68) são evidências. Mas não evidências como sintomas de uma doença insana que culminaria em um surto psicótico (na perspectiva etiológica do criminoso nato). Apenas evidências de que era necessária uma intervenção precoce, e ainda branda, nessas situações de risco, para evitar a marginalização e uma posterior situação mais grave, a qual não tardou a se consolidar ${ }^{13}$.

Isso porque a intervenção estatal é permitida - e obrigatória -; uma vez que a família, base da sociedade, tem especial proteção do Estado, incumbindo a este a assistência a cada um dos que a integram, através de mecanismos capazes de coibir a violência no âmbito de suas relações ${ }^{14}$. E essa proteção deve ser integral à criança e ao adolescente, já que é proibitiva qualquer forma de negligência, discriminação, exploração, violência, crueldade e opressão, punido na forma da lei qualquer atentado, por ação ou omissão, aos seus direitos fundamentais ${ }^{15}$.

Não por menos, na aplicação desses três princípios, ainda é necessária a observação do melhor (maior) interesse de Luíza. Deverá ser aplicado o mecanismo efetivo de proteção considerando-se o maior interesse para a situação concreta. Não é legítima a formulação de decisões genéricas, aplicáveis a casos semelhantes. Apesar de circunstâncias similares, as medidas de proteção ou as socioeducativas devem ser diferenciadas conforme as necessidades especiais da criança ou adolescente em situação de risco.

\footnotetext{
${ }^{13}$ Princípio da intervenção precoce mínima informado implicitamente pelo Estatuto da Criança e do Adolescente. ${ }^{14}$ Art. 226, caput e $\S 8^{\circ}, \mathrm{CF}$ : é o que ficou preconizado como o princípio da obrigatoriedade da intervenção estatal. 15 Arts. 227, $\S 3^{\circ}, \mathrm{CF}$ c/c arts. $1^{\circ}$ e $5^{\circ}$, Lei n $\mathrm{n}^{\circ} 8069 / 1990$ (ECA): princípio da proteção integral.
} 
Revista da Faculdade de Direito-RFD-UERJ - Rio de Janeiro, n. 31, jun. 2017

Por isso, mais apropriado do que falar em evidências de uma ação violenta futura é falar na criminalização de Luíza: a constituição de uma realidade social capaz de qualificar uma conduta desviante e de promover uma reação social contra o estigmatizado como criminoso. É apenas um círculo vicioso, ou mesmo um mutualismo de causas e consequências.

Ao Estado negligente - quanto à tutela de uma intervenção precoce e obrigatória, da proteção integral e da consideração do melhor (maior) interesse - é simples justificar a necessidade de criminalização e punição da conduta tida como desviante. De fato, parece legítimo à maioria punitivista colocar as falhas interventivas precoces do Estado como evidências do processo que levou o criminoso nato a cometer atos insanos. É mesmo a solução mais óbvia diante da frequência, da dramatização e da morbidez com que os delitos são transmitidos e assimilados: um evidente descompromisso com as questões de ordem estrutural que culminam no crime.

\section{A psicopatia amoral, a lógica dos indícios perversos e a expiação do louco social}

Não obstante, sem esquecer a incompatibilidade do modelo criminológico positivis ta, há que se admitirem episódios que ultrapassam os limites do processo de criminalização. Crimes estes decorrentes, também e de fato, de uma inimputabilidade ou semi-imputabilidade por doença ou transtornos mentais do agente. Contudo, diante do contexto do grande encarceramento, as variações da imputabilidade surgem com tendências à expiação e à estigmatização do louco social. Nesse sentido, Cristina Rauter e Salo de Carvalho põem em evidência a incompatibilidade dos discursos e práticas psi (RAUTER, 2010) para, então, promover a perspectiva antipsiquiátrica (CARVALHO, 2013a, p. 270-311).

E essa outra cisão ao modelo positivista foi além do rótulo do crime: associou o estigma da loucura a Luíza. Quando de seu diagnóstico, em sucessivos laudos, a equipe do psiquiatra forense Humberto Soares Guimarães atestou - através de testes e entrevistas - que ela sofria de psicopatia amoral (BARROS, 2010, p. 48-54).

Conforme J. Alves Garcia (1979), autor que fundamentou os laudos da equipe técnica, as psicopatias - ou personalidades psicopáticas -, geralmente apresentam intelecto normal, ou até acima da média; além de distúrbios da conduta ética ou antissociais; são indiferentes às medidas educacionais, meios corretivos ou correcionais; caracterizam-se por enfermidade fronteiriça da personalidade; manifestam-se precocemente, já na infância e na adolescência; e apresentam anormalidade dos instintos e da conduta (GARCIA, 1979, p. 204). 
Revista da Faculdade de Direito-RFD-UERJ - Rio de Janeiro, n. 31, jun. 2017

No entanto, essa caracterização não é exaustiva, como mostra evidente a descrição do sintoma nuclear: "incapacidade de aprender pela experiência as normas de sociabilidade e do bom senso, ou ainda de adaptar-se pela assimilação e pela correção às modificações ou inovações ocorrentes no grupo comunal ou histórico em que deve actuar o indivíduo" (GARCIA, 1979, P. 204). Nesse rol característico, mas não taxativo, insere-se, ainda, a incapacidade de sentir arrependimento ou remorso, além da ausência de escrúpulos, porque não são dotados de sentimentos éticos e sociais.

Seguindo para a classificação objetiva, o mesmo autor entende o psicopata amoral, psicopatologia diagnosticada em Luíza, como fronteiriços "insensíveis, antissociais ou perversos, destituídos de compaixão, de vergonha, de sentimentos de honra e conceitos éticos"; assim como "não sentem simpatia pelas pessoas de seu grupo social e têm conduta lesiva ao bem-estar, à ordem estabelecida" (GARCIA, 1979, P. 205). Além disso, "mostram-se precocemente voluntariosas, cruéis, insinceras, cometem faltas, não se adaptam nos colégios, e, já na maturidade, tornam-se incessíveis, impiedosas, brutais e impulsivas. São frias, pérfidas e arrogantes" (GARCIA, 1979, p. 205). E, não por menos, "seu campo de ação antissocial é o das ofensas físicas contra pessoas e a propriedade, reincidindo frequentemente nos delitos contra a vida" (GARCIA, 1979, p. 205).

No âmbito criminal, seus delitos são marcados pela insensibilidade: chegam a vangloriar-se do feito. São indiferentes à opinião pública. A intensidade de seus instintos associada à falta de inibição resulta nos mais perversos delitos. Não são passíveis de reeducação ou regeneração, já que não apresentam consciência moral. As medidas correcionais ou carcerárias tendem a aumentar ou requintar a forma de delinquir ou de manipular a ação da Justiça. De certo que os psicopatas amorais, diante dessa classificação, vivem em um estado permanente de embriaguez moral: apresentam desinibição da autocensura, agressividade e descontrole instintivo.

De fato, todos os indícios levam a apontar que Luíza sofria desse tipo de psicopatia amoral. Isso se mostra evidente até aos mais leigos, quando da comparação da conduta de Luíza, narrada por Eneas Barros, com a descrição tematizada por J. Alves Garcia. Isso porque, em uma tradição vinculada a uma tetralogia de valores (NIETZSCHE, 1998), chega a parecer mesmo lógica essa atribuição aos ditos psicopatas de qualquer característica associada ao mal, constantemente incitada no cidadão médio pela opinião pública. No entanto, esses portadores do transtorno da personalidade antissocial - em outro termo psiquiátrico -, tais como Luíza, 
Revista da Faculdade de Direito-RFD-UERJ - Rio de Janeiro, n. 31, jun. 2017

são pessoas comuns, assim como os mesmos cidadãos que insurgem em favor da moralidade e da juridicidade, e contra "os vampiros da vida real" (SILVA, 2011, p. 42).

$\mathrm{Na}$ verdade, essa tendência psiquiátrica corresponde a uma perspectiva etiológica das ciências criminais, que justifica um processo de individuação (definição das essências do estigmatizado como psicopata) e de ocultamento do não igual, de modo a pretender criar um mundo de belas aparências (CARVALHO, 2013a, p. 121). E ainda é pouco adequada aos padrões epistemológicos da contemporaneidade, uma vez que é insustentável a avaliação clínica de rotulamento e exposição pública social (CARVALHO, 2013b, p. 5).

Essa tendência opera a partir de elementos genéricos e propensos à manipulação. Genéricos e manipuláveis porque revelam julgamentos valorativos que dependem da interpretação íntima acerca da realidade e da experimentação formadora da consciência de cada pessoa. Além disso, porque são observáveis em qualquer ser humano, não podem fazer parte de um "diagnóstico retrospectivo" (CARVALHO, 2013b, p. 6), de uma busca incessante por indícios selecionados na vida do agente que sugerem um ato criminoso futuro. Na verdade, superficialidade, eloquência, egocentrismo, megalomania, mentiras, trapaças, manipulação, não manifestação de emoções em determinadas circunstâncias, impulsividade, deficiência no autocontrole, necessidade de excitação, falta de responsabilidade, problemas comportamentais precoces e comportamento transgressor (SILVA, 2008, p. 68-91) são características facilmente observáveis em qualquer personalidade humana, seja ela psicopática ou altruísta.

Por isso, é que Salo de Carvalho (2013b, p. 6) denuncia que esse tipo de diagnóstico apresenta em sua essência dois grandes equívocos. O primeiro deles diz respeito às falhas conceituais: aos significados e limites na interpretação das características taxativas para aferição de psicopatia. De certo, as categorias que rotulam essa psicopatologia apresentam conceitos dúbeis e voláteis (CARVALHO, 2013b, p. 6). Se a equipe de psiquiatras constatou que Luíza apresentava uma vaidade marcadamente psicopática - por, dentre outros fatores, apresentar-se com saias e vestidos curtos o suficiente para exibir as coxas em posição tendenciosa, mesmo depois de afirmar que não ligava para namoro - (BARROS, 2010, p. 52), houve uma clara substituição dos julgamentos dos fatos por juízos valorativos morais.

Em verdade, essas valorações, que aparentemente são acolhidas dentro da moldura interpretativa psiquiátrica positivista, não encontram sustentáculo em âmbito jurídico. Isso porque, em decorrência de seu conteúdo moral (limite material) e da impossibilidade de 
exercício do contraditório (limite processual), os juízos de valores são inválidos em termos processuais (CARVALHO, 2013b, p. 6).

São necessários dados concretos e nexo de causalidade com o fato imputado para que a valoração judicial seja legítima, já que o Estado Democrático de Direito se propõe a responsabilizar as pessoas pela infração de bens jurídicos, e não por suas individualidades humanas (CARVALHO, 2013b, p. 6). Daí porque se questionar acerca da idoneidade dos laudos da psicóloga Eulineide, que atestam a conduta infratora e violenta de Luíza pautando-se em relatos como os de que, quando era criança, matou um gato torcendo o seu pescoço, ou de ter, em uma briga com uma amiga na escola, furado-a com um lápis, e ainda de ter feito um relato do crime de forma fria e dissimulada (BARROS, 2010, p. 61).

Disso decorre a evidência do segundo equívoco denunciado por Salo de Carvalho. A falha metodológica referente ao objeto de investigação: grupos previamente rotulados como criminosos (CARVALHO, 2013b, p. 6.). O pesquisador parte de uma hipótese preconcebida: a psicopatia. Não diagnostica através dos fatos, mas primeiro rotula (ou mesmo condena) seu objeto de estudo à psicopatologia, para então ir atrás de fatos que indiciem (desvinculados da pretensão probatória) a conduta criminosa. Não existe a essencial imparcialidade ética para o diagnóstico. Esse nada mais é do que um diagnóstico retrospectivo: seria uma aproximação do que Franco Cordero designa como "primado das hipóteses sobre o fato", a forma mentis que caracteriza o estilo inquisitorial da reconstrução da verdade (apud CARVALHO, 2013b, p. 6.).

Mas aí não se consubstancia o mais grave equívoco desse tipo de rotulação. A pior delas é a falha ética: "a aniquilação da pessoa; substituindo sua identidade pelo rótulo inextirpável do "sujeito perigoso"” (CARVALHO, 2013b, p. 7). A análise da história de vida de Luíza associase à rotulação do louco social para produzir uma expectativa quanto à sua conduta futura. Ela será perpetuamente condenada socialmente. Repreendida na íntima convicção de cada pessoa que the cruzar o caminho à espera ansiosa do desdobrar do drama, que culminará na interseção entre o crime e a loucura.

E o que se pretende não é reduzir a psiquiatria, uma das ciências criminais integradas, a um novo sistema dogmático, com a pretensão da vontade de verdade e de exegese. Ou então se estaria legitimando o retorno à psiquiatria biológica: a pretensão do diagnóstico e da catalogação de sintomas totalmente objetivos e científicos.

Em verdade, entende-se que não é possível um padrão técnico, já que à facticidade é imprescindível a análise concreta. O que pode ser insanidade em uma situação, em outra é 
apenas um hábito ou uma característica de diferenciação humana. Por outro lado, não se podem fazer juízos valorativos: porque o direito exige a legalidade. A solução é associar cada ciência à sua moldura interpretativa. É definir os limites em que começa o direito e onde termina a psiquiatria, sem esquecer as restrições inerentes a cada uma delas para que a relação serviente entre as ciências criminais seja legítima.

É necessário, ainda, desconsiderar a ideia orientada pelo paradigma etiológico e causal do positivismo italiano de que o crime é um ente natural, o criminoso um ser atávico e a pena regeneradora. Além disso, é imperativo atentar para o fato de que "o discurso punitivo hoje hegemônico no campo criminal circunscreve, para os discursos e práticas psi, uma função de produção de estigmas, desvinculada de propostas propriamente terapêuticas" (RAUTER, 2010, p. 199). Por isso, pretende-se exortar o saber psiquiátrico da legitimação de intervenções violentas sobre o público vulnerável.

\section{Da descrença em um perfil psicopático pré-estabelecido}

Nessa temática, propõe-se a descrença em um perfil psicopático pré-estabelecido. E, para não incorrer nesses erros ou para alertar os aplicadores clínicos que não os cometam, é que Guido Arturo Palomba mantém o conceito de condutopatia ${ }^{16}$ no tripé: comprometimento da (I) afetividade (inadequada resposta emocional), da (II) conação e volição (intenção mal dirigida e movimento voluntário sem inibição) e da (III) capacidade de autocrítica. Ele propõe (apenas em exemplificação) um leque de características que podem decorrer desses três tipos de comprometimento, dependendo a classificação do caso concreto. Ao contrário do direito - que quanto mais literal e taxativo, mais segurança jurídica, em regra -, a psiquiatria abre muito mais espaço à interpretação do profissional, que deve ser baseada preferencialmente em sua experiência clínica, e não em seus juízos valorativos.

Assim, geralmente é atribuída ao condutopata a semi-imputabilidade penal (pelo perito juspsiquiatra) e a semi-responsabilidade do ato praticado (pelo juiz): em virtude da sua perturbação da saúde mental. Essa parcial capacidade, no entanto, só poderá ser imputada se houver nexo causal entre a condutopatia e o delito praticado. Semi-imputabilidade porque, normalmente, o condutopata apresenta os três comprometimentos categóricos na estrutura

\footnotetext{
${ }^{16}$ Ao contrário da literatura majoritária, que insiste em denominar os transtornos de personalidade como psicopatia, Guido Arturo Palomba, emprega o termo condutopatia. Isso porque a ideia literal que se atribui a um psicopata é a de um indivíduo doente mental (psyche, mente, e pathos, doença). Mas, na verdade, o condutopata é um fronteiriço, em regra; está na linha imaginária entre a doença mental e a normalidade. (PALOMBA, 2003, p. 515).
} 
psíquica já mencionados. No entanto, tem consciência de seus atos, não demonstra insuficiência de inteligência, da memória ou da sensopercepção (PALOMBA, 2003, p. 516).

Se por um lado são perturbados mentais que apresentam inadequada resposta emocional, intenção mal dirigida, movimento voluntário sem crítica (PALOMBA, 2003, p. 516); por outro mantêm íntegras todas as outras funções mentais. Eles entendem a inconformidade moral e jurídica de seus atos, mas são incapazes de inibir suas intenções, daí a voluntariedade do ato.

Outra característica marcante da condutopatia é a ausência de remorso, angústia e ansiedade (PALOMBA, 2003, p. 516). E isso decorre desse primeiro comprometimento da afetividade. O condutopata não se angustia pelo mal decorrente de sua conduta imoral e/ou antijurídica. O único remorso que sente é quando do fracasso de seu comportamento delituoso. E a única ansiedade vivida é a decorrente da previsão das consequências pessoais que recairão sobre si diante da ação mal sucedida. Quando homicida, por exemplo, ele não lamenta as vidas perdidas, os filhos sem pais, a dor da família. Sofre pelo desconforto de ficar preso, ou, quando narcisista, pelo seu crime imperfeito.

Essa tríade de comprometimento (afetividade, conação-volição e capacidade de autocrítica) é desenvolvida acompanhando o passo da desenvoltura individual. Sim, há a propensão à condutopatia. Palomba propõe que o "padrão de comportamento surge no curso do desenvolvimento individual, como fruto de fatores constitucionais e de vivências pessoais, e desvia-se dos padrões culturais, do meio social no qual se desenvolveu" (PALOMBA, 2003, p. 516). Esse padrão de comportamento, ou conduta doente, inicia-se na adolescência - ou na infância, em sua forma precoce. Mas isso não significa que o psicopata nasce como tal - ou ainda mais gravemente como criminoso, na perspectiva do paradigma etiológico. Pode passar por toda a vida sem cometer nenhum ilícito jurídico, ou até mesmo moral.

Quanto às causas, segue-se também o esquema de três bases: (I) epiléptica, (II) esquizofrênica e (III) encefalopática. Por bases entendem-se as entidades clínicas que se manifestam de forma frustras, convergindo para distúrbios de conduta clinicamente semelhantes, de modo que o condutopata pode apresentar sintomas similares à encefalopatia minor, à epilepsia comportamental ou à esquizofrenia simples (PALOMBA, 2003, p. 517). Adverte-se que esses distúrbios primários podem ser cumulativos ou não. Em regra, cada tipo de condutopatia tem sua base definida, mas pode associar-se a outras bases ou mesmo divergir quanto às origens: sempre dependerá do caso concreto, da avaliação clínica. 
Revista da Faculdade de Direito-RFD-UERJ - Rio de Janeiro, n. 31, jun. 2017

Em resumo, o psicopata (ou condutopata) não é, necessariamente, sedutor, sanguinário e de uma inteligência beirando à genialidade. Pode ser. Como qualquer ser humano. Em verdade, são apenas pessoas capazes de ampliar os limites impostos pela sociedade, já que têm comprometida a capacidade de inibição. Por isso - pelo comprometimento da afetividade, da conação-volição e da capacidade de autocrítica - é que são entendidos como indivíduos de desenvolvimento mental incompleto.

E, apesar dessa caracterização da psicopatologia de Luíza, não se cuidará da propositura de um diagnóstico: por falta de profissionalização na área psiquiátrica e ainda pela necessidade do exame pessoal em um laudo técnico, já que são vedados laudos psiquiátricos baseados na dinâmica do crime. No entanto, é necessário um mínimo de empatia para perceber que Luíza também era uma pessoa comum. Eneas Barros propõe que "as intrigas, as repreensões, a inveja e às vezes a violência fazem parte da rotina de muita criança" (BARROS, 2010, p. 61). De fato. O que faltou a Luíza foi um desenvolvimento mental completo capaz de inibir atitudes violentas. A sua ampliação (ou desconsideração) dos limites morais a levou às mais drásticas consequências em resposta emocional inadequada a situações sociais rotineiras.

\section{Das críticas à psiquiatria tradicional para além do critério mais adequado}

Essa não é, no entanto, a resposta dada pela antipsiquiatria ao transtorno da personalidade antissocial de Luíza. Para essa vertente, na figura de seu maior representante Thomas S. Szasz -, doença mental é algo que não existe: há apenas uma má representação de papéis que são repudiados pelos familiares e médicos do dito louco (SZASZ, 1982, p. 230-231). Não existem sintomas clínicos, mas apenas variações do comportamento humano; e os "personificadores e as pessoas que aceitam suas personificações, criam um mito, culturalmente compartilhado" (SZASZ, 1982, p. 231). Igualmente, Cooper, influenciado por Szasz, propõe que a loucura é apenas um rótulo (COOPER, s.d.).

A antipsiquiatria, no entanto, parece ter um caráter fortemente político na concepção da doença mental como mito social (PALOMBA, 2003, p. 37). Também aparenta cair no equívoco do primado das hipóteses sobre os fatos (Cordero apud CARVALHO, 2013, p. 7). Se de um lado a psiquiatria biológica compromete-se com a produção de estigmas, a antipsiquiatria parte de contestações sociopolíticas para enquadrar suas ideias à realidade da doença mental. Há um evidente descomprometimento das duas vertentes com propostas propriamente terapêuticas. 
De fato, a loucura concebida como o iminente perigo da violência ou da insensatez não existe. Mas entendida como a desordem química cerebral é experimentável. Mais adequado é criar um meio termo, ou de forma mais apropriada: fazer uso desses dois extremos da psiquiatria para direcionar-se a uma terceira perspectiva.

É esse o caminho da tendência de Salo de Carvalho, que, apesar de intitulá-la antipsiquiatria, teoriza de forma mais flexível. Ou pelo menos aceita as exceções inerentes ao estudo da desordem mental. O que ele objetiva, em verdade, é evidenciar as rupturas realizadas pela antipsiquiatria referentes ao tratamento asilar manicomial, de modo a incorporá-las em analogia à esfera prisional (CARVALHO, 2013, p. 271).

É preciso entender a doença mental como um fenômeno que se origina em razões e interações sociais, conforme a interpretação de Aniyar de Castro (1983, p. 168-169). No entanto, é imprescindível também reconhecer a separação feita entre doenças orgânicas do cérebro das doenças da mente (CARVALHO, 2013, p. 290), que são construídas, aqui sim, através de um juízo de valor. As doenças orgânicas do cérebro partem de déficits neurológicos inquestionáveis, enquanto que as doenças da mente são apenas problemas do viver, mas não defeitos ou alterações do sistema nervoso. Nesse sentido, as perspectivas de Salo de Carvalho e Guido Arturo Palomba podem trabalhar em sintonia para entender-se que a psicopatia é uma doença orgânica do cérebro.

De fato, nos termos taxativos de J. Alves Garcia, o transtorno da personalidade antissocial seria mesmo uma doença da mente, já que os sintomas clínicos são dúbeis e manipuláveis em favor da construção de um mito social. A perspectiva de Palomba, ao contrário, aponta um desenvolvimento mental incompleto associado às entidades clínicas que se manifestam de forma frustra (bases epiléptica, encefalopática e esquizofrênica), no sentido de que há o comprometimento da afetividade, da conação-volição e da capacidade de autocrítica. O psicopata é desprovido da capacidade inibidora, além de responder a circunstâncias cotidianas de forma emocionalmente inapropriada.

Em sede dessa controvérsia, tem razão Zaffaroni ${ }^{17}$, quando insurge em favor do respeito às garantias e direitos fundamentais dos usuários dos serviços de saúde mental, afirmando que a regulação jurídica é a única proteção disponível. Além disso, propõe, de forma aparentemente

\footnotetext{
17 A "única protección para todos consiste en una regulación jurídica que garantice un tratamiento óptimo, conforme a los recursos terapéuticos, y respetuoso de la dignidad, para cualquier paciente psiquiátrico, sin distinguir entre los pacientes psiquiátricos absueltos por inimputables por la justicia y quienes nunca se hubi esen hallado en esse trance" (Zaffaroni apud CARVALHO, 2013, p. 304).
} 
alheia ao racional, a indistinção entre doentes mentais que cometeram delitos daqueles que não o fizeram.

Mas, em verdade, é uma questão lógica: se o delito só ocorreu pela doença mental - e por isso a inimputabilidade - certamente será decorrente de um sintoma clínico, passível de diagnóstico em qualquer indivíduo que apresente a desordem mental identificada. Há apenas manifestações sintomáticas variáveis de acordo com o organismo de cada sujeito. Portanto, cessados os sintomas e recuperado o insano, não há porque mantê-lo sob custódia, ainda que ambulatorial, com o pretexto da temibilidade da reincidência. Sob pena de voltar-se ao conceito ultrapassado de periculosidade. Ou ao conceito de pena como vingança.

A questão mais delicada refere-se ao eficientismo do tratamento para transtornos de conduta, tais como a psicopatia: como fazer cessar os sintomas e recuperar o insano. Não existe tratamento clínico reconhecido. E essa não é uma questão pautada no conceito frágil de periculosidade.

Para a psiquiatria atual, o cárcere ou o asilo ${ }^{18}$ é o destino do criminoso alienado mental. No entanto, na fronteira entre as duas instituições correcionalistas, subsistem os psicopatas, categoricamente limítrofes: "lúcidos para casas de alienados e insuficientemente irresponsáve is para a prisão" (RAUTER, 2003, p. 114).

Cristina Rauter (2003, p. 115) fundamenta que esse tipo de semi-responsabilidade representa, para o poder psiquiátrico, um instrumento de patologização cada vez maior de atos e de indivíduos. Enquanto que, à justiça, adquire um caráter de solução cômoda à criminalidade, de modo a mascarar a problemática política e social.

A personalidade psicopática é definida de forma contraditória: se por um lado merece um rótulo de anormalidade, em oposição, é irrecuperável. Segundo Rauter (2003, p. 118), a psiquiatria "ao mesmo tempo em que dispõe de uma entidade nosográfica capaz de dar conta da contestação às leis, do extremismo e da excentricidade, recua diante da tarefa de disciplinálos”. Transfere à justiça penal o ônus de impor autoridade e responsabilidade aos psicopatas através de uma instituição dita disciplinar modelo: a prisão.

No entanto, é necessário reconhecer que, ainda no sentido da proposição de Cristina Rauter (2003, p. 125), que o psicopata, por sua inadequação carcerária ou terapêutica, é o “ponto

\footnotetext{
${ }^{18}$ Com a ampliação da idéia de alienação mental proposta porEsquiol, além de aumentar a recorrência da loucura, delegou-se parte da responsabilidade correcionalista jurídica à psiquiatria. Além disso, reconhecendo-se a possibilidade ininteligível de cura dos monomaníacos, o tratamento psiquiátrico adquire caráter de prisão ilimitada, com o pretexto terapêutico.
} 
claro deixado pela maquinaria disciplinar, o eterno indisciplinado que, no interior de sua engrenagem, coloca-a perigosamente em questão, demandando a formulação de novas estratégias que no momento não se fazem presentes".

Em verdade, é importante revisitar a proposição de Zaffaroni em referência ao respeito às garantias e direitos fundamentais dos usuários dos serviços de saúde mental. O Estado Democrático de Direito não pode optar por desconstruir o princípio da dignidade da pessoa humana ${ }^{19}$. A ressocialização de um psicopata, embora reconhecidamente inalcançável pela psiquiatria, deve ser perseguida. Isso porque qualquer integrante do povo, seja ele insano ou não, tem direito à restauração. O Estado não pode se pretender abrir mão de qualquer cidadão, ainda que psicopata. As garantias fundamentais são indistintas e impessoais. E o ônus da possível reincidência, tanto do psicopata ou de qualquer outro transgressor dos limites jurídicos dito normal, é da coletividade.

Embora esse discurso da justiça restaurativa beire ao utópico (ou ao extremo absurdo da inadequação) em algumas situações, foi a alternativa escolhida pelo constituinte para efetivar os direitos fundamentais. No entanto, a celeuma não diz respeito à discussão acerca da adequação da preferência política do Estado. É imperativo, apenas para não incorrer no ultraje aos princípios básicos do Estado Democrático de Direito, que essas garantias fundamentais e o constitucionalismo não sejam insultados por um ou outro falso momento revolucionário aparentemente democrático.

Além disso, falar em isolamento definitivo (ou de internação sem duração delimitada) no âmbito jurídico é um grande equívoco. Isso porque tanto o Supremo Tribunal Federal20 quanto o Superior Tribunal de Justiça ${ }^{21}$ entendem que, sendo vedada a clausura de caráter perpétuo pela Constituição Federal2 $^{22}$, a medida de segurança - equiparável à pena no gênero sanção penal - deve sujeitar-se a um período máximo de duração. Em igual sentido segue o Pacto de São José da Costa Rica, o qual o Brasil é signatário, quando garante que o direito à integridade pessoal abrange o respeito à plenitude psíquica e moral; a proibição de pena ou tratos cruéis, desumanos ou degradantes, já que toda pessoa privada da liberdade deve ser tratada com respeito devido à dignidade inerente ao ser humano; além de garantir que penas

\footnotetext{
${ }^{19}$ Art. $1^{\mathbf{o}}$, inciso III, CF.

${ }^{20} 1^{\text {a }}$ Turma, HC 107432, j. 24/05/2011; $2^{\text {a }}$ Turma, HC 97621, j. 02/06/2009.

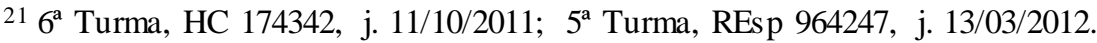

22 Artigo 5", inciso XLVII (Princípio da limitação das penas), alínea "b".
} 
Revista da Faculdade de Direito-RFD-UERJ - Rio de Janeiro, n. 31, jun. 2017

privativas de liberdade devem ter por finalidade essencial a reforma e a readaptação social dos condenados $^{23}$.

Nesse sentido, Salo de Carvalho (CARVALHO, 2013a, p. 306) recomenda a extinção das medidas para inimputáveis por doença mental, com uma ressalva: abre exceção a determinações para irresponsáveis mentais que tenham protagonizado casos graves. É exatamente assim que ele se refere, porém torna vago o conceito de casos graves. Para o autor, a regulamentação psiquiátrica é mais adequada, e eficiente, do que a legislação penal.

Nesse sentido, para além da discussão do critério mais adequado, é necessário estabelecer limites materiais e formais à intervenção no caso de Luíza; e essa limitação diz respeito ao tempo de tratamento, às possibilidades de tratamentos ambulatoriais e a previsão de altas progressivas (esfera penal material) e controle judicial dos procedimentos (esfera processual penal) (CARVALHO, 2013a, p. 306).

\section{Considerações Finais}

Uma perspectiva crítica e restrita aos fatos do caso de Luíza não se rende aos propósitos tradicionais de um instinto punitivista subjugado a uma tendência de estigmatização do louco social. Assim como não anseia extremar suas proposições em favor de qualquer projeto político radical. Exige-se mais do que podem oferecer as posições herméticas da criminologia clínica ou da criminologia crítica. Da psiquiatria biológica ou da antipsiquiatria. À unidade paradigmática sobrepujou-se a malha complexa de integração das ciências criminais. E sua essência requer a análise das inúmeras condicionantes e circunstâncias variáveis do comportamento humano, ao passo que, com isso, tende a reconduzir os cidadãos ao interesse não pelo clamor de justiça, mas pela participação na esfera política ansiosa por intervenções estatais eficientes.

Na verdade, a análise do caso de Luíza não enseja o direcionamento a políticas públicas referentes à criminalização. É evidente que tanto os movimentos punitivistas, defensores do endurecimento das penas, quanto os movimentos abolicionistas têm conquistas que contribuem para crença ou descrença no direito penal. Basta lembrar a experiência americana, em que durante as décadas de 50 a 80 observou-se uma progressão social e econômica consideráve is não acompanhadas pelo decréscimo da criminalização. No entanto, com a adoção, na década

\footnotetext{
${ }^{23}$ Art. $5^{\circ}, 1,2$ e 6, Pacto de São José da Costa Rica.
} 
de 90, de uma legislação penal bem mais rigorosa apresentou os menores índices de criminalidade já registrados. Por outro lado, a experiência brasileira sugere que duras penas não são a alternativa mais adequada. A Lei dos crimes hediondos, tida como a solução da criminalidade violenta, não contribuiu para alterar a incidência das mais graves violações a bens jurídicos. O número de homicídios, por exemplo, entre 1993 e 2002, aumentou 62,3\%, bem superior ao acréscimo populacional de 15,2\% no mesmo período (UNESCO, 2007).

A questão não se situa em punir ou abolir. Uma vez que um dos fundamentos da República Federativa do Brasil é o pluralismo político ${ }^{24}$, decorrente de uma realidade igualmente plúrima de minorias e singularidades. O padrão que faz jus às necessidades da política de combate à criminalidade e das particularidades de cada meio social é que deve ser considerado em sua eficiência. Porque o paradigma dominante é o aparente paradoxo da pluralidade de paradigmas.

O que se impugna, de forma ilustrada no caso de Luíza, é a estigmatização do louco social pelo crime e pela loucura e o aparente clamor por justiça. Mas, em verdade, associa-se a ânsia por altas penas à perspectiva da vingança privada, em condução à renúncia dos princípios de uma democracia constitucionalista.

Existe, portanto, uma espécie de mutualismo intermitente entre o populismo punitivo e a opinião pública em favor da criminalização de um público vulnerável. Enquanto a mídia imprime nos indivíduos a expiação ao criminoso, a dramatização terrorista e a morbidez do crime, despotencializando o sentimento coletivo; o governo populista oferece soluções punitivas aparentemente óbvias de extirpação da criminalidade. E para essa alternativa ser instituída requer a sujeição das garantias fundamentais e do compromis so constitucionalista à fantasia do tirano majoritário.

Parece mesmo uma teoria da conspiração aos olhos da ilusória feridade do cidadão médio, que insiste em conceber o crime como algo natural a determinados indivíduos. No entanto, isso não é ignorância. É cegueira voluntária ${ }^{25}$. Existe cegueira voluntária em escalas épicas ${ }^{26}$ : quando da receptividade do discurso da expiação ao criminoso tematizado pela mídia, da rotulação cultural da loucura, do fascínio pela violência; ou quando da retificação de projetos

\footnotetext{
${ }^{24}$ Art. $1^{\circ}, \mathrm{V}, \mathrm{CF}$.

25 "A cegueira voluntária é um conceito legal que significa que, se há informação que você pode e deve saber, mas de alguma forma você decide não saber, a lei considera que você é um cego voluntário. Você escolhe não saber." (HEFFERMAN, 2013).

${ }^{26}$ Importa esclarecer que a construção técnica da escrita desse raciocínio ampara-se analogicamente na oratória desenvolvida por HEFFERMAN (2013).
} 
políticos do populismo punitivista em desconsideração dos princípios do Estado Democrático de Direito. Também se pode constatar a cegueira voluntária em escalas pequenas, como no caso de Luíza, pré-julgada pela inquisição social e aniquilada como pessoa, culminando na substituição de sua identidade pelo rótulo inextirpável de menina-vampiro.

$\mathrm{Na}$ verdade, a ignorância consciente é vinculada pelo sentimento de descrença na coletividade (HEFFERMAN, 2013). Ou ainda pelo sentimento elitista, em referência à exposição do louco social: a negação da perspectiva de que o crime é vivenciado por qualquer do povo, mas que a criminalização é direcionada a setores vulneráveis da sociedade.

É evidente, pois, a contrapartida do cidadão ativo, capaz de se fazer voz ativa e contestadora, participante dos processos históricos e das consolidações dos princípios fundamentais, para insurgir em favor do devido processo legal penalista em oposição à inquisição social. E essa perspectiva não ambiciona um posicionamento hermético legalista. Mas tão somente anseia o exercício da liberdade para efetivar a vontade primeira do povo renovando os direitos fundamentais e as conquistas políticas históricas - e, ao mesmo tempo, limitar as ilegítimas transposições coletivas fundamentadas em falsos momentos revolucionários.

Portanto, mais apropriado do que vincular à identidade de Luíza o título de meninavampiro e ansiar por sua clausura perpétua ou por penas degradantes é desmitificar o sensacionalismo midiático a serviço de políticas populistas do instinto punitivista, negar sua estigmatização pelos rótulos do crime e da loucura e confrontar os contrapesos da função de tutela do Estado com sua pretensão punitiva. Por isso, tanto se argumentou pela adoção da perspectiva das ciências criminais integradas: para atender às peculiaridades do caso em favor da incidência da técnica jurídica adequada e para não incorrer no perigo da estigmatização social. 
Revista da Faculdade de Direito-RFD-UERJ - Rio de Janeiro, n. 31, jun. 2017

\section{Referências bibliográficas}

ANDRADE, Vera Regina Pereira de. Do Paradigma Etiológico ao Paradigma da Reação Social: Mudanças e Permanências de Paradigmas Criminológicos na Ciência e no Senso Comum. Sequência. Florianópolis: UFSC, v. 16, n. 30, 1995.

ANIYAR DE CASTRO, Lola. Criminologia da Reação Social. Rio de Janeiro: Forense, 1983.

ARGUELLO, Katie. Do estado social ao estado penal: invertendo o discurso da ordem. Anais do Congresso Paranaense de Criminologia. Londrina, 2005.

BARATTA, Alessandro. Criminologia Crítica e Crítica do Direito Penal. Rio de Janeiro: Renovar, 2002.

BARROS, Eneas. 15:50. Teresina: Bagaço, 2010.

BATISTA, Nilo. Criminalidade Econômico-financeira, Intervenção no XIII Congresso Internacional de Direito Comparado. Veredas do Direito, Belo Horizonte, v. 4, n. 7, p. 87-93, 2007.

BATISTA, Vera Malaguti. Introdução Crítica à Criminologia Brasileira. Rio de Janeiro: Revan, 2011.

BECKER, Howard. Los Estraños. Buenos Aires: Tiempo Contemporáneo, 1971.

CARVALHO, Salo de. Antimanual de Criminologia. São Paulo: Saraiva, 2013a.

CARVALHO, Salo de. Mentes Perigosas na Academia: sobre plágios, responsabilidades, diagnósticos e estigmas. Boletim IBCCRIM, ano 21, n. 245, 2013.

COOPER, Dan. Psiquiatria e Antipsiquiatria. São Paulo: Perspectiva, s.d.

CRIMES macabros abalam Floriano. Jornal O Dia, Teresina, 25 nov. p. 1 e 7. 1998. № 12080.

FERRAZ JR., Tércio. A Violência Razoável. Jomal Folha de São Paulo, Folhetim no 149 , 1981.

FERRI, Henrique. Princípios de Direito Criminal. São Paulo: Saraiva, 1931.

GARCIA, J. Alves. Psicopatologia Forense. Rio de Janeiro: Irmãos Pongetti Editores, 1958.

GAROFALO, Raffaele. Criminologia: estudo sobre o delito e a repressão penal. São Paulo: Teixeira \& Irmãos Editores, 1983. 
HEFFERMAN, Margaret (03-2013). [Vídeo]. Os Perigos da "Cegueira Voluntária”. TED: Ideas worth spreading. Disponível em: http://www.ted.com/talks/margaret_heffernan_the_dangers_of_willful_blind ness? source=face book\&language=pt-br. Acesso em: 18 out. 2013.

JAKOBS, Günther. Strafrecht. Duncker - Humblot, n. 1 a 16, p. 5-12, 1992.

LOMBROSO, Cesare. O Homem Criminoso. Rio de Janeiro: Ed. Rio, 1983.

LOPES JR., Aury. Direito Processual Penal. São Paulo: Saraiva, 2013.

MARTÍNEZ, Mauricio. Populismo Punitivo, Maiorias e Vítimas. ABRAMAVOY, Pedro Vieira e BATISTA, Vera Malaguti (orgs.). Depois do Grande Encarceramento. Rio de Janeiro: Revan, p. 313-327, 2010.

NIETZSCHE, Friedrich. Além do Bem e do Mal. São Paulo: Companhia das Letras, 2002.

NIETZSCHE, Friedrich. Genealogia da Moral. São Paulo: Companhia das Letras, 1998.

PALOMBA, Guido Arturo. Tratado de Psiquiatria Forense: Civil e Penal. São Paulo: Atheneu, 2003.

PETTIT, Philip. Teoria da Liberdade. Belo Horizonte: Del Rey, 2007.

RAUTER, Cristina. Criminologia e Subjetividade no Brasil. Rio de Janeiro: Revan, 2003.

RAUTER, Cristina. Discursos e Práticas Psi no Contexto do Grande Encarceramento. ABRAMAVOY, Pedro Vieira e BATISTA, Vera Malaguti (orgs.). Depois do Grande Encarceramento. Rio de Janeiro: Revan, p. 195-205, 2010.

SILVA, Ana Carolina Barbosa. Mentes Perigosas: o psicopata mora ao lado. Rio de Janeiro: Objetiva, 2008.

SZASZ, Thomas. O Mito da Doença Mental. São Paulo: Círculo do Livro, 1982.

UNESCO. Mapa da Violência IV: os jovens do Brasil, 2004. Disponível em: http://unesdoc. unesco.org/images/0013/001351/135104porb.pdf. Acesso em: 18 out. 2013.

YOUNG, Jock. A sociedade excludente: exclusão social, criminalidade e diferença na modemidade recente. Rio de Janeiro: Revan, 2002. 